\title{
Dynamic position change at colonoscopy improves adenoma detection
}

\author{
Subrata Ghosh MBBS MD FRCPC FRCP FRCPE, Editor-in-Chief, Marietta lacucci MD PhD
}

$\mathrm{C}$ olonoscopy has led the way with regard to quality assurance in gastroenterology and endoscopy services. Widespread adoption of colonoscopic screening and surveillance to detect colonic adenoma has driven much of the quality improvement. Improved bowel preparation regimens, better training of both trainees and trainers, optimizing withdrawal time of colonoscope to permit careful inspection, use of magnetic endoscopic imaging, better colonoscopies that now permit retroflexion in the right colon, regular and routine monitoring of colonoscopic performance and feedback, and single balloon-assisted colonoscopies in patients who failed conventional colonoscopy have all contributed to more efficient, effective and safer colonoscopies. Patient satisfaction with colonoscopy is high (1), and quality improvement driven by national guidelines and training has been encouraging (2).

Dynamic position changes during colonoscope withdrawal was pioneered by the St Mark's Hospital group from London, United Kingdom, and was incorporated into their training program. This group conducted a randomized crossover trial and reported that position changes during colonoscopic withdrawal significantly improved polyp and adenoma detection rates (3). In the current issue of the Journal, Köksal et al, from Turkey (4) (pages 509-512), confirmed this in a randomized study in which the investigators randomly assigned patients 1:1 to examination in either the left lateral position during colonoscope withdrawal or other positions (Table 1). An increase in adenoma detection rate of $9.8 \%$ in the transverse colon, splenic flexure, descending and sigmoid colon was noted in the group examined by dynamic position changes.

Dynamic position change is intuitive because air naturally rises to the highest position. Such position changes result in better distension with less insufflation of air, shifting of fluids and residues, and opening tight angles at flexures. Hence, this may also help ease insertion. However, the patients need to be lightly sedated and moving from the left lateral to supine position is relatively easy, but moving to the right lateral position is more cumbersome. It is possible that simply a 'tilt' to the right side rather than full right lateral decubitus may suffice, but this needs to be proven. Most Canadian colonoscopists do not routinely practice dynamic position changes at colonoscopy. On current evidence, a supportive case can be made for such practice to be adopted. This will also emphasize good practice during colonoscope withdrawal, not just in the time taken, but optimum positioning, carefully looking behind folds, optimizing luminal distension and suctioning all residues and fluid. While optimum insertion technique to reach the cecum makes a good colonoscopist, it is withdrawal technique that makes a great colonoscopist. Certainly, such meticulousness is not compatible with hurry, but the rewards are much greater, especially for the patient.

\section{TABLE 1}

Dynamic patient positioning during colonoscope withdrawal (Köksal et al, pages 509-512)

\begin{tabular}{|c|c|c|c|}
\hline \multirow[b]{2}{*}{ Segment of colon } & \multicolumn{3}{|c|}{ Position } \\
\hline & $\begin{array}{l}\text { Left lateral } \\
\text { decubitus }\end{array}$ & $\begin{array}{c}\text { Supine } \\
\text { decubitus }\end{array}$ & $\begin{array}{l}\text { Right lateral } \\
\text { decubitus } \\
\text { (? Right tilt) }\end{array}$ \\
\hline Cecum & $x$ & & \\
\hline $\begin{array}{l}\text { Ascending colon and } \\
\text { hepatic flexure }\end{array}$ & $x$ & & \\
\hline Transverse colon & & $x$ & \\
\hline $\begin{array}{l}\text { Splenic flexure, } \\
\text { descending colon }\end{array}$ & & & $x$ \\
\hline Sigmoid colon & & & $x$ \\
\hline Rectum & $\mathrm{x}$ & & \\
\hline
\end{tabular}

\section{REFERENCES}

1. Chartier L, Arthurs E, Sewitch MJ. Patient satisfaction with colonoscopy: A literature review and pilot study. Can J Gastroenterol 2009;23:203-9.

2. Leddin DJ, Enns R, Hilsden R, et al. Canadian Association of Gastroenterology position statement on screening individuals at average risk for developing colorectal cancer: 2010. Can J Gastroenterol 2010;24:705-714.

3. East JE, Bassett P, Arebi N, Thomas-Gibson S, Guenther T, Saunders BP. Dynamic position changes during colonoscope withdrawal increase adenoma detection: A randomized, crossover trial. Gastrointest Endoscopy 2011;73:456-63.

4. Köksal AŞ, Kalkan İH, Torun S. A simple method to improve adenoma detection rate during colonoscopy: Altering patient position. Can J Gastroenterol 2013;27:509-12. 


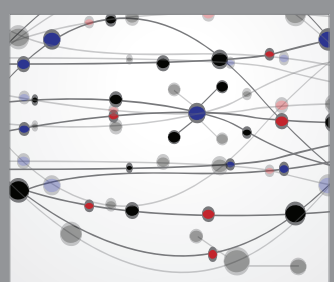

The Scientific World Journal
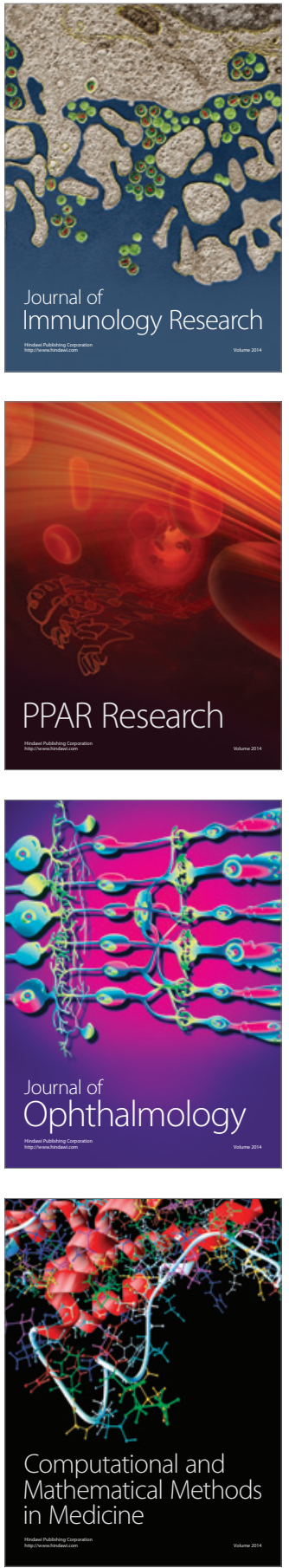

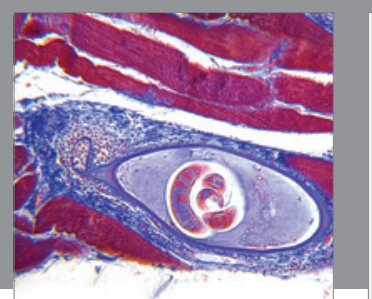

Gastroenterology Research and Practice

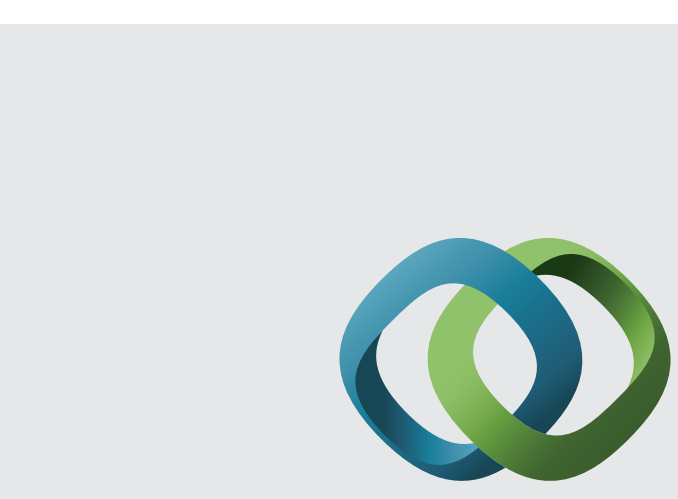

\section{Hindawi}

Submit your manuscripts at

http://www.hindawi.com
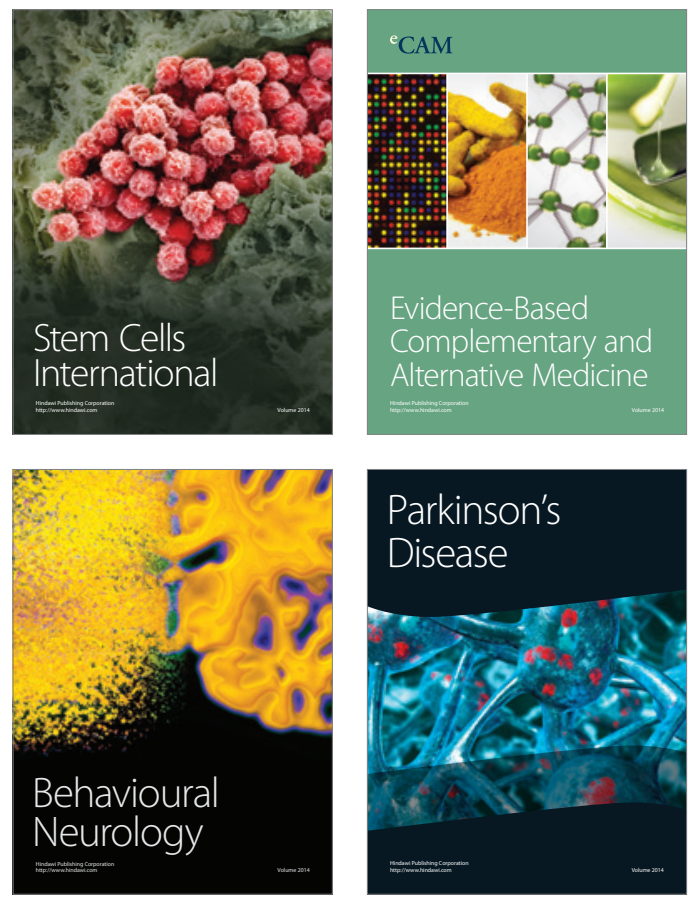
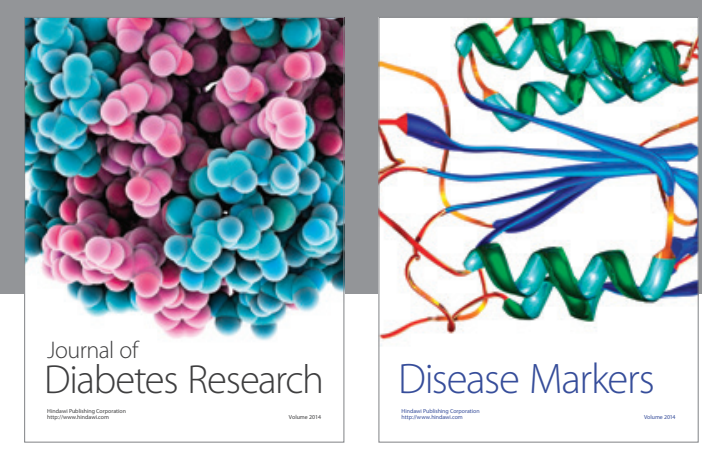

Disease Markers
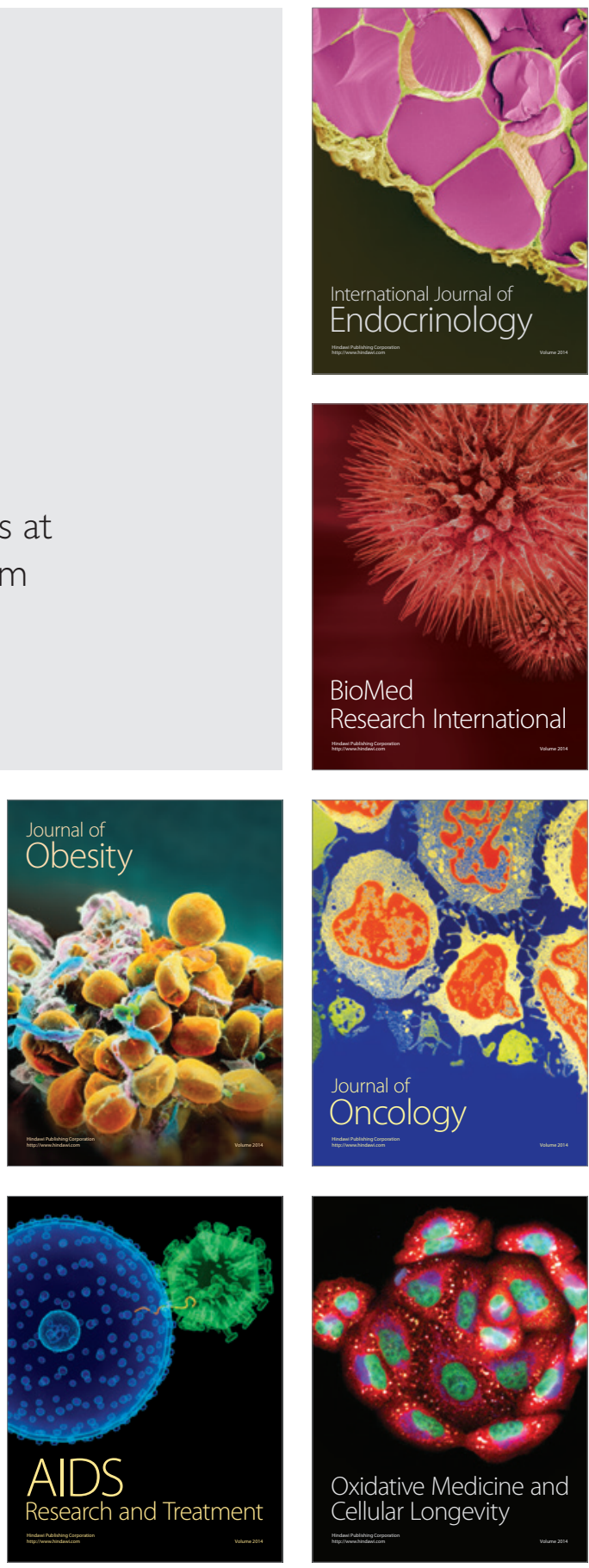